\title{
PATOLOGÍA, ESCRITURA Y GÉNERO EN EL FIN DE SIGLO: ALMA CONTEMPORÁNEA Y MANUAL DEL PERFECTO ENFERMO
}

\author{
Alba del Pozo García \\ Centre Dona i Literatura \\ a.depozo9@gmail.com
}

RESUMEN / ABSTRACT

Este artículo aborda dos ensayos españoles sobre la enfermedad publicados en el cambio de siglo XIX-XX, de José María Llanas Aguilaniedo (Alma contemporánea, 1899) y de Rafael Urbano (Manual del perfecto enfermo, 1911). Se examina el modo en el que asumen la neurosis masculina como una manifestación positiva e inevitable de la vida moderna, en línea con el ambiente cultural de un fin de siglo marcado por los discursos médicos y la correlación que establecen entre el genio, la producción artística y las patologías psiquiátricas. Ambos textos se identifican con la retórica clínica y plantean un propósito curativo explícito. Sin embargo, en lugar de limitarse a reproducir el binomio enfermo/sano, lo van a problematizar, puesto que la categoría de enfermedad que desarrollan se va a desligar del modelo médico para desplazarse al terreno de la subjetividad, la escritura y la identidad.

Palabras ClaVE: literatura española, fin de siglo, enfermedad, José María Llanas Aguilaniedo, Rafael Urbano.

This paper analyses two Spanish essays on illness published during the fin de siècle: José María Llanas Aguilaniedo’s 1899 Alma contemporánea and Rafael Urbano’s 1911 Manual del perfecto enfermo. The focus lies on how masculine neurosis is read as a sign of modern struggles in a fin de siècle culture characterized by the hegemony of medical discourses and the relationship between genius, artistic production, and psychiatric pathologies. Both texts are associated to medical discourses and suggest healing strategies. In this scope, the typical ill/health opposition undergoes a critical turn. In fact, these texts depict a notion of illness that undermines medical rhetoric, placing illness in the field of subjectivity, writing and identity.

KEY WORDS: Spanish literature, fin de siècle, illness, José María Llanas Aguilaniedo, Rafael Urbano. 


\section{INTRODUCCIÓN}

En este artículo examinaré cómo dos ensayos españoles sobre la enfermedad publicados en el cambio de siglo XIX-XX, de José María Llanas Aguilaniedo (Alma contemporánea, 1899) y de Rafael Urbano (Manual del perfecto enfermo, 1911), asumen la neurosis masculina como una manifestación positiva e inevitable de la vida moderna. Esta postura se contrapone al clima cultural del fin de siglo, en el que los discursos médicos establecen una correlación entre el genio, la producción artística y las patologías psiquiátricas. Además de abordar la vinculación entre enfermedad y creación, estos textos sitúan la convalecencia y el reposo en la esfera de la lectura. Ambos volúmenes se presentan como una terapia para un lector ideal, potencialmente enfermo o convaleciente. Desde distintas perspectivas, tanto Alma contemporánea como Manual del perfecto enfermo ${ }^{1}$ se identifican con la retórica clínica y plantean un propósito curativo explícito. Sin embargo, en lugar de limitarse a reproducir el binomio enfermo/sano, ambos textos lo van a problematizar, e incluso lo socavarán, puesto que la categoría de enfermedad que desarrollan se va a desligar del modelo médico para desplazarse al terreno de la subjetividad, la escritura y la identidad.

Así, Llanas propondrá un arte curativo, adecuado para el estado de esa alma contemporánea que dice analizar, y Urbano, haciendo honor al título de su texto, formula un verdadero manual para orientar la actitud del neurasténico a la búsqueda de curación. Esta preocupación común se sostiene, además, en una premisa problemática: si por un lado reconocen al artista/intelectual como un neurótico, por otro extienden esas metáforas al conjunto de la sociedad. La neurosis resulta así una enfermedad tan común que se asume como un problema colectivo, complicando de este modo la individualización y exclusión del loco y el concepto mismo de una normatividad asociada a la salud, que deviene una excepción remota. Ambos ensayos, por lo tanto, participan en la desarticulación de las mismas estructuras de saber que dicen reproducir: al convertir la convalecencia en un lugar de lectoescritura, colapsarán la legitimidad de la voz médica, apropiándose de su retórica y resituándola en el terreno de una subjetividad enferma. Asimismo, la distinción entre el médico/sano y el paciente/enfermo, en la que el primero se presenta fuera del discurso como una voz autorizada para el diagnóstico, va a resultar 
inoperativa, ya que será el enfermo quien termine ocupando la posición de enunciador y receptor de las narrativas sobre la enfermedad.

Atenderá también a la problemática presencia de la feminidad en ambos textos, que reelabora el paradigma decimonónico de la mujer enferma, perpetuamente histérica, reclinada y afectada por diversos males (Dijkstra). En su estudio sobre el decadentismo y la retórica de la enfermedad, Spackman analiza la controvertida presencia del género en las recurrentes escenas de convalecencia finisecular, señalando, por un lado, cómo la mujer es expulsada de ellas, mientras que por otro sus atributos se incorporan a la configuración del enfermo masculino, que se convierte, bien en un andrógino, bien en un ventrílocuo que habla a través del cuerpo de la mujer: "Indeed, woman is expelled in order that her qualities may be abstracted and reassigned to the convalescent himself" (61). Esta lectura apunta, por un lado, a la erosión del sistema binario de sexos en el fin de siglo, pero por otro lado explica la continuidad de un concepto de feminidad pasivo y objetualizado, ya apuntado también por Felski ("The Counterdiscourse of the Feminine") o Spackman (42). La debilidad, el estado de reposo y la indolencia de este nuevo convaleciente masculino lo emplaza al fin y al cabo en el territorio de los atributos femeninos, entendidos como una suerte de convalecencia natural.

La problemática construcción del enfermo como un sujeto masculino aunque desvirilizado supone una fisura en el binomio que entiende a la mujer en términos patológicos, aunque la va a seguir excluyendo del -ahora privilegiadoterreno de la mirada enferma. Mi propósito es abordar esta cuestión como un signo de una crisis de fin de siglo que desarticula las oposiciones binarias entre feminidad/masculinidad y salud/enfermedad (Nouzeilles, "Narrar el cuerpo propio" 154), pero que a su vez está insertada en el centro mismo de las estructuras del poder que encarnan los discursos médicos.

El discurso psiquiátrico supone, por lo tanto, un marco ineludible, ya que origina el retrato del sujeto moderno como un cuerpo enfermo, especialmente en el caso del artista y el intelectual. Las teorías de la degeneración que gobernaban el paradigma científico del siglo XIX asumían la existencia de sujetos desviados de una normalidad general (Morel 15), que podían suponer una amenaza física y moral al resto de la sociedad (Pick, Campos et al.). Esta retórica, estrechamente asociada con una voluntad de control y poder sobre aquellos cuerpos e identidades que no se ajustaban a la moralidad de las clases medias, se desplaza en el fin de siglo hacia el terreno de la crítica artística (Cardwell 95, Nouzeilles, Ficciones somáticas 151). En este contexto, Cesare 
Lombroso desarrolla sus teorías sobre l'uomo di genio ${ }^{2}$, con las que cataloga el genio como una patología mental. También cabe mencionar la paradójica formulación de los franceses Magnan y Legrain sobre la existencia de un tipo de "dégénérés supérieurs" (19 y ss.), que dan una vuelta de tuerca a las teorías de la degeneración. Max Nordau también es otra referencia omnipresente en este imaginario, con sus célebres diatribas contra el artista moderno en Degeneración, dos tomos que en 1892 diagnosticaban de degenerados a la gran mayoría de movimientos artísticos finiseculares.

Mientras Nordau clama contra el artista como un enfermo peligroso que debe extirparse del cuerpo social, las posiciones de Magnan, Legrain y Lombroso resultaban mucho más ambiguas, y dan cuenta del clima en el que se insertarán los textos de Llanas y Urbano. El italiano, a pesar de entender el genio como neurosis, también parece comprender la admiración que sienten las masas hacia estos perfiles, diferenciados de la gran mayoría de sujetos. De hecho, Lombroso tampoco va a denegar el valor artístico de sus creaciones. Al contrario, en la sexta edición revisada de Genio e folia se permite incluso matizar a Nordau, reafirmando la existencia del genio en la nómina de autores que su colega y discípulo consideraba únicamente enfermos (Lombroso XXI). El criminalista establece así una relación correlativa entre la calidad estética y la enfermedad: "[il] vero genio larvato di alienazione (paranoia in genere, monomania, epilessia), i cui prodotti erano, si può dire, di tanto più sublimi quanto più era il corpo malato, anzi perchè era malato" (XXI-XXII).

Por su parte, Magnan y Legrain complican todavía más este panorama al establecer la posibilidad de degeneración superior, que se distancia del sujeto atrasado que habita el lumpen urbano. Esta oximorónica categoría invierte la propia noción misma de cuerpo degenerado, al mostrar una variante que se presenta como una hipertrofia fruto de un proceso evolutivo exagerado:

Mais à côté de ces lacunes, de ces atrophies, il n'est pas rare de constater de véritables hypertrophies: au milieu de cet irrégulier ensemble se détache, en une saillie d'autant plus frappante que le reste est plus nul, une faculté brillante, une prodigieuse mémoire, une remarquable facilité d'élocution, une imagination vive, riche manteau qui cache bien des misères (Magnan 39).

2 Que van desde el primer estudio publicado en 1864, Genio e folia, hasta una sexta edición definitiva en 1894, L'uomo di genio in rapporto alla psichiatria alla storia ed all'estetica. 
El colapso hacia el final de siglo de conceptos como el de evolución se reproducirá hasta la saciedad en los ensayos de Llanas y Urbano. Lo que podría leerse como confusión o ambigüedad retórica, sin embargo, constituye un marco discursivo complejo, que permite tanto el refuerzo de los dispositivos disciplinarios sobre los sujetos como su desarticulación. Las formulaciones de Magnan y Legrain (1895) dan otra vuelta de tuerca a la teoría de la degeneración como desviación de un tipo de normalidad humana. Para Magnan, la degeneración se organiza ya según metáforas evolucionistas en las que el sujeto desviado no deriva de una normalidad ideal, si no que se articula como un proceso, "un mouvement de progression d'un état plus parfait ver un état moins parfait” (Magnan y Legrain 79) 3 .

Este imaginario abre la puerta a la posibilidad de leer la creación artística desde el discurso médico, interpretando la escritura como el síntoma de una figura autorial enferma: "The nineteenth-century theorization of mental illness passed first through the sick body of the degenerate: sick bodies produced sick thought" (Spackman 1989: VII). Este contexto va a producir dos movimientos contrarios que se retroalimentan entre sí: por un lado, un proceso de patologización sobre textos y autores que encarnan a menudo los discursos psiquiátricos. Desde las propuestas foucaultianas, se ha trabajo por extenso la amplia relación entre medicina mental y poder, así como los modos en los que el discurso médico produce y clasifica la diferencia ${ }^{4}$. Por otro, trabajos ya clásicos (Sontag, Gilman) han puesto de relieve que lo patológico puede articularse, además de como una tecnología del poder (Foucault), como una categoría cultural que sujeta diversas tensiones y reescrituras. Ambos textos resultan, en ese sentido, una buena muestra de la dimensión cultural de la locura que ha trabajado Huertas (Una historia cultural de la psiquiatría), a través de los cuales mostrar la necesaria relación entre psiquiatría y subjetividad. En estos casos, además, son los discursos psiquiátricos los que son sometidos a diversos actos de reapropiación y desarticulación a través de la escritura, incluso por parte de las mismas estructuras de poder en las que se insertan. Este será el caso de los textos analizados, que reivindicarán

\footnotetext{
Sobre las diferencias, encuentros y desencuentros textuales entre Morel, Magnan, Legrain y Lombroso a raíz de la contradictoria noción de degeneración superior, véase Huertas (Locura y degeneración 154 y ss.).

Véase Huertas (Los laboratorios de la norma), para el caso español y Armus (Entre médicos y curanderos, Disease in the History of Modern Latin America y "La enfermedad en la historiografía”), para el caso latinoamericano.
} 
la identidad enferma como modo legítimo, e incluso mejorado, de mirar y producir una realidad.

\section{EL CUERPO DEL ALMA CONTEMPORÁNEA}

En contraste con su reiterada ausencia en gran parte de la bibliografía crítica sobre el período, José María Llanas Aguilaniedo (Fonz 1875-Huesca 1921) resulta, a mi juicio, una figura clave en el fin de siglo. Llanas nace en Fonz (Huesca), hijo de farmacéuticos, desde donde se traslada a Barcelona para proseguir la saga familiar y estudiar farmacia; es decir, para formarse en los principios de un positivismo científico que empezaba ya a erosionarse, como podrá inferirse del recorrido posterior. Como he estudiado en otro lugar (Del Pozo), los primeros artículos que publica aparecen en el Boletín Farmacéutico y acusan un entusiasmo por la ciencia que plantea una relación transparente entre la mirada y el conocimiento de la realidad, según la cual la observación de la naturaleza trae el saber sobre el mundo empírico sin fisura alguna.

Sin embargo, la fe en el saber y el progreso rápidamente deja paso a la duda y la sospecha (Broto 52 y ss.). De hecho, será en el propio Boletín -es decir, en las mismas estructuras que sustentan el saber científico- donde empieza a complicarse la relación del observador con el objeto observado. Tras esta época de auge y crisis simultáneas en torno al positivismo, Llanas se desplaza en 1896 a Andalucía tras lograr una oposición como farmacéutico militar, y empieza a tomar contacto con círculos modernistas. Será por estos años, indica Broto (101 y ss.), cuando se geste la escritura de Alma contemporánea, compaginada con la publicación de diversos textos en la prensa andaluza sobre las nuevas corrientes estéticas: que el antaño científico convencido se convierta al modernismo resulta más sintomático que contradictorio, en tanto que las nuevas narrativas culturales dependen $-\mathrm{y}$ socavan a su vez- un imaginario común en el que los discursos científicos ocupan un lugar hegemónico. En 1898, Llanas se trasladará a Madrid por motivos laborales, donde se interesará a partes iguales por el modernismo, con la publicación Alma contemporánea al año siguiente, y las corrientes científicas del momento como la criminología lombrosiana. Acude al Ateneo y al Laboratorio de Criminología dirigido por Rafael Salillas -donde por 
cierto, conocería a Rafael Urbano- ${ }^{5}$ y fruto de estas actividades publicará con Bernaldo de Quirós el estudio de criminología La mala vida en Madrid (1901). No sería hasta 1902 que llegaría su primera novela, Del jardín del amor, al año siguiente publicaría Navegar pintoresco y unos años más tarde, Pityusa (1907). Sin embargo, su actividad literaria después de esta última novela se reduce considerablemente, hasta su último artículo, publicado en $1911^{6}$. Uno de los elementos biográficos que sin duda llama más la atención de la figura de Llanas son sus últimos años, en los que según Broto (391 y ss.) sufre algún tipo de enajenación mental, ingresando en más de una ocasión en hospitales militares, para finalmente retirarse a Huesca, donde muere en 1941. Además de la probable ironía que supone la locura de un defensor de las teorías de Lombroso, esta narración de un recorrido vital me parece demasiado significativa como para pasarla por alto: la figura biográfica de Llanas se constituye así en función de las mismas estructuras que determinan personajes como el del científico loco, el intelectual regeneracionista o el refinado neurótico. Con ello no pretendo justificar biográficamente una producción literaria: antes al contrario, me atrevería a señalar que la narración biográfica y la literaria responden a un imaginario común, en que la locura del escritor puede leerse como algo más que una deliciosa casualidad. Si me he detenido en estos detalles, además de con un propósito introductorio y contextual, es porque Alma contemporánea, entre otras cuestiones, apuntala una concepción del escritor enfermo a través de la cual Llanas también va a construir, en mi opinión, su propia figura autorial.

Como ya he mencionado, Alma contemporánea aparece en 1899. Este texto quiere ser, en primer lugar, una reflexión sobre el estado del arte contemporáneo. En segundo, delinea una propuesta estética, el “emotivismo”, que quiere erigirse en alternativa a ese panorama, y responder a su vez a las inquietudes artísticas y nerviosas del sujeto moderno que trazaba la psiquiatría. El ensayo se divide entre una revisión de las corrientes artísticas de la época y del "alma” contemporánea y otra en la que se desgranan las principales claves

5 A quien cita brevemente en $A C$ y que también colaboraría en La mala vida en Madrid. "Rafael Urbano está entre las primeras amistades de Llanas en el Madrid de 1898, año dedicado a la redacción de Alma contemporánea. Lo trató Llanas, sobre todo, en la sección de Ciencias Morales y Políticas del Ateneo, presidida por Salillas y cuyo secretario era por entonces Bernaldo de Quirós” (Broto, en Llanas Aguilaniedo, Alma contemporánea $30)$.

$$
\text { Bajo el título “Hoy como ayer”, en la revista Vida Socialista. }
$$


del emotivismo. A pesar de las coincidencias que puede plantear el examen de Llanas con el modelo de Nordau -al que cita a menudo-, el aragonés mantiene una actitud totalmente distinta a sus predecesores, ya que apuesta por una modernidad que asume la decadencia y la enfermedad como males imprescindibles para el progreso ${ }^{7}$.

En la frase que abre el ensayo ya aparece un modelo de conocimiento que, si bien se inserta en el paradigma de la degeneración, apunta también a una perspectiva que entiende la decadencia como otro modo de mirar lo real: "No obstante ser el sol tan bello al salir como al ponerse (Verlaine), el alma contemporánea, por analogía sin duda, comprende mejor la belleza de la puesta que la de la aurora" (Llanas 7). Tras esta declaración de crepusculares intenciones, aclara sin embargo las razones científicas que conllevan a esta irremediable conclusión:

el trabajo intelectual o físico crea fatigados de los dos órdenes y éstos no pueden engendrar más que escrofulosos, tísicos, impotentes, estaturas bajas, etcétera, e histéricos. De todo este deshecho de la raza, están llenas nuestras ciudades, en las cuales, lejos de abundar los genios primitivos, inventores con inteligencia de niño y facultad inventiva de gigante, no se ven más que inteligencias viejas, cansadas ya por herencia (8).

Esta modernidad convertida en decadencia y agotamiento se explica a través de metáforas médicas individuales y colectivas. Por un lado, el sentimiento de ocaso del individuo finisecular se presenta como elemento clave para abordar la propuesta estética que intentará definir Llanas. Por otro, la sensibilidad decadente no puede entenderse sin la teoría de la degeneración, puesto que la metáfora de la puesta de sol simbolizando la sensibilidad contemporánea se sostiene sobre las teorías psiquiátricas que apuntan a un sistema nervioso atrofiado por los excesos de la vida moderna, y que encarna toda una legión de individuos que trasladan sus patologías a la producción artística.

Sin embargo, mientras la psiquiatría indaga en busca de lesiones orgánicas, las narrativas finiseculares, y especialmente el decadentismo, realizarán

Sobre Llanas véase la monografía de Broto, y ya centrados en $A C$, los trabajos de Pitarch, Ara, Calvo y Fillière. En ellos se destaca tanto la relación del ensayo con la medicina, como las enormes diferencias en el planteamiento y el modo de comprender el sentimiento estético finisecular. 
gracias a estas mismas estructuras un redescubrimiento de la vida psíquica -y a menudo patológica- de los sujetos. Así, el alma contemporánea de Llanas solo puede configurarse a través de un cuerpo enfermo, fruto de la degeneración hereditaria (la decadencia de la raza) y/o ambiental (el espacio urbano): "El poema de la vida interior se dirige también al alma, pero por el lenguaje de las sensaciones, y hoy más especialmente, por el de la debilidad del sistema nervioso; el de los sentidos, de ordinario alucinados" (89). Al establecer esta correlación entre la indagación literaria en el yo y la neurastenia, el redescubrimiento del "alma" por parte de la literatura finisecular (Ara 47-48) apunta hacia una cuestión más compleja que la de un mero cambio de focalización (Litvak 111), puesto que supondrá la erosión del dispositivo disciplinario que despliega la psiquiatría.

Llanas parte de una hipótesis bastante común, que compartirá con Urbano: la enfermedad es una cuestión colectiva que afecta a casi todos los estratos sociales. El aragonés establece dos focos de infección fundamentales asociados al espacio de la ciudad: por un lado, la clase obrera, afectada de degeneración y embrutecimiento, y por otro, las clases altas e intelectuales, víctimas de la neurastenia (Llanas 12). En esta argumentación, que también va a reproducir Urbano, la enfermedad pasa a ocupar una posición hegemónica, y a entenderse como un fenómeno común más allá de la oposición entre normalidad y anormalidad. La salud, paradójicamente, se sitúa en los márgenes, articulándose como una excepción al conjunto social.

Sin embargo, frente a las argumentaciones higienistas, que presuponen una patología más o menos colectiva que hay que curar o solventar, la mirada de $A C$ plantea un matiz muy distinto: a pesar de sus propósitos terapéuticos, el ensayo aborda este marco patológico como un lugar estético de creación y lectura en el que el sujeto enunciador oscila entre el científico y el esteta.

\subsection{EL EMOTIVISMO Y LA NEUROSIS}

Para abordar las posibles soluciones a las neurosis de la vida moderna, Llanas acude a la estética para proponer lo que él llamará un arte emotivista, destinado a aquellos sujetos convalecientes de sus propias patologías mentales, tanto creadores como lectores.

El texto bebe así de la relación entre creación y neurosis, establecida por la psiquiatría, que asumía al artista como un enfermo potencial que plasma en su obra los síntomas de una patología. La escritura, por lo tanto, pasa a incorporarse al análisis clínico, situándose además en la encrucijada que 
media entre lo individual y lo colectivo: "En el libro, en el cuadro y en el teatro, la humanidad reproduce hoy día sus trastornos nerviosos, sus delirios y aberraciones, sus manías y extravagancias, esa serie variada de fenómenos que la llevan como de la mano, haciéndola marchar a grandes pasos hacia la locura" (Llanas 11). Además de articular al sujeto enfermo en el agente de la mirada sobre el arte y la naturaleza, Llanas lo perfila también como el receptor ideal de su propuesta estética, que teóricamente actúa como un paliativo al estado nervioso de dichos individuos. $A C$ se aproxima así a un prudente discurso de salud y verdad, que le blinda ante posibles críticas por su defensa de las corrientes artísticas finiseculares. El emotivismo, de este modo, se describe como una necesidad de los tiempos:

En estos estados de exaltación, producidos por cualquier excitante (en cuya categoría podemos incluir la fiebre de la vida moderna), las manifestaciones intelectuales superiores dejan su puesto a la emoción y todo hasta que lo más insignificante constituye materia harto apropiada para despertar y sacudir violentamente la emotividad del individuo, que ríe y llora sin causa, apreciando de cada objeto o situación únicamente la fase que impresiona su sensibilidad extraordinaria y anormal. Un arte, pues que tradujera exactamente el estado de alma de los hombres de esta época, sería un arte esencialmente emotivo (153-154).

Si las fronteras entre el científico positivista y el artista en crisis son especialmente tenues en el fin de siglo (Bernheimer 42), en el caso de Llanas Aguilaniedo resultan además difíciles de separar. Primero, porque el autor examina al individuo moderno desde la lupa del psiquiatra, diagnosticándole una sensibilidad “anormal” que requiere de algún tipo de acción higiénica. Segundo, porque el remedio que propone se desliga del paradigma clínico, para desplazarse al de las corrientes artísticas finiseculares. El emotivismo se plantea así como fruto del alma enferma de la contemporaneidad, dirigida teóricamente a un lector igual de enfermo o convaleciente.

En resumen, la propuesta de Llanas, supone la búsqueda de una obra ideal, generada por un autor ideal, con unos contenidos y una forma ideales susceptible de ser recreada con el concurso de un lector ideal [...]. Este "lector ideal" también se tiene en cuenta en los estudios médicos y psicológicos contemporáneos, que atribuyen al receptor 
de una obra artística -concebida "patológicamente"- una especie de “analogismo espontáneo" (Calvo 44) ${ }^{8}$.

Estamos, por lo tanto, ante una probable fisiología (patológica) del lector, que se justifica por un contexto en el que la necesidad emotiva se ha convertido en el nuevo vicio de la modernidad, cuyos riesgos no solo se sitúan en el campo de lo moral, sino que constituyen una auténtica amenaza para la salud individual y colectiva. La sensibilidad del sujeto contemporáneo, por lo tanto, se basa en una emotividad sostenida sobre el concepto de enfermedad nerviosa, y justificada por la medicina del momento. En este contexto, el giro retórico que ofrece Llanas presenta una propuesta artística que funciona como canalización al ansia de emociones modernas, que de no dirigirse adecuadamente derivaría en un peligro serio para el individuo y el resto del cuerpo social:

El hombre busca, y seguirá buscando cada vez con mayor apasionamiento, a la emoción, por vicio, como el dipsómano busca el alcohol y el morfinómano, el alcaloide del opio. Hay varias maneras de levantar el ánimo decaído, cada una con fenómenos y sensaciones que le son propios; hay quien escoge una vida de crápula, como hay quien fuma opio o bebe láudano; la vida activa llena de impresiones distintas, de la emoción de lo nuevo y de lo que está por venir, vida de agitación y de inquietud constante, de eretismo continuo del sistema nervioso, produce también una excitación agradable, un bienestar y vivacidad parecidos a los que producen el alcohol o cualquiera de los otros excitantes, para el que se ha habituado a su uso; el organismo, en esas condiciones, dura poco (Llanas 237).

A pesar de constituirse desde la estética, el emotivismo se va a legitimar en este contexto como una necesidad médica, destinado a paliar los males de gran parte de la población. Sin embargo, la propuesta de Llanas tampoco pretende restaurar un estado primitivo de virilidad y salud, sino que se orienta a fomentar el reposo y la contemplación de las vicisitudes del yo. El objetivo terapéutico o regenerador de la propuesta se diluye, en parte, al realizar una lectura atenta: si la emotividad es un vicio contemporáneo o un

Esta construcción del receptor enfermo se sitúa en una amplia red intertextual, que permite relacionar el texto con diversas producciones literarias, estéticas y científicas como las de Huysmans, Guyau o Ribot (Calvo) y filosóficas como Nietzsche (Pitarch). 
tipo de neurosis, el emotivismo no parece estar enfocado a erradicarlo, sino a fomentarlo, al ofrecer únicamente el mismo alivio momentáneo que dan las drogas cuyos abusos denuncia. Más bien parece ejercer el efecto contrario, al apuntar directamente a la contemplación estética y la sensibilidad neurótica del receptor, en un proceso sospechosamente parecido a los excesos del arte moderno denunciados por Nordau. Nótese, además, que si para la psiquiatría la lectoescritura se constituye en síntoma de un cuerpo enfermo -creadores degenerados y obras perniciosas-, aquí se da la vuelta a esa concepción, convirtiéndose en la solución y no en el problema a las patologías de la vida moderna. Esto supone una subversión importante en cuanto al modelo de conocimiento de la retórica médica, que se colapsa al mostrarlo como un dispositivo ineficaz en el abordaje de las neurosis contemporáneas.

Tratar de rehabilitar la emoción ennobleciéndola, hasta constituir con ella la base de un arte eminentemente sincero [...]; reservar a la emoción, en una palabra, no el papel de excitación fugaz del momento, sino el de manantial fecundísimo de sentimientos e ideas, que puestas en un todo al servicio de lo bello por excelencia, dignifiquen en vez de degradar, he ahí el fin del emotivismo y sus rasgos principales como tendencia, que pongo a la consideración de la gente nueva (240).

El emotivismo posee por lo tanto una aplicación práctica: a fin de evitar recurrir a sustancias como el opio, el láudano o el alcohol, el sujeto finisecular debe refugiarse en la estética. Su propuesta está, por lo tanto, destinada a una mirada enferma que busca en el arte consuelo a su condición. Frente al modelo patologizador de la medicina, $A C$ sitúa la escritura en un marco ambiguamente terapéutico, que viene a colapsar las retórica del poder de una psiquiatría empeñada en clasificar cualquier comportamiento heterodoxo desde los cánones de la enfermedad y la locura. Así, la propuesta de Llanas no solo puede parecer novedosa en el terreno de la estética y la creación artística del fin de siglo, sino que apunta directamente a dinámicas de poder y control sobre las identidades, al reivindicar la neurosis, a través del emotivismo, como el verdadero lugar de progreso cultural.

En este marco de dilución de límites identitarios, ese enfermo fin de siècle se va a construir desde unas metáforas de género complejas: el degenerado de Llanas, lector ideal de la terapéutica emotivista, se asume desde un masculino puesto en duda, débil y feminizado. ¿Qué ocurre sin embargo, con la categoría mujer? En las próximas páginas profundizaré en esta cuestión, que como era de esperar tampoco se resuelve de forma definitiva: si por un lado se van a 
socavar los límites del género, por otro se va a intentar, con un éxito relativo, mantener la feminidad dentro de unos márgenes convencionales.

\subsection{LA FEMINIDAD COMO PATOLOGÍA Y TROPO ARTÍSTICO}

Dado que la asociación entre feminidad y patología recorre todo el discurso médico del siglo XIX (Ortiz, Jordanova, Jagoe “Sexo y género”), catalogando a la enfermedad como un proceso de feminización y a la feminidad como una patología en potencia, no es de extrañar la tendencia generalizada a reproducir el mismo binomio a la hora de abordar el sujeto y la sociedad finiseculares. Aunque el matiz importante resta en el valor positivo o negativo que se le da a la enfermedad, lo cierto es que anunciar la feminización de individuos y colectividades de todo pelaje es uno de los recursos más comunes del imaginario finisecular. $A C$ también va a abordar este proceso, otorgándole no obstante un valor positivo, que aproxima al texto hacia la posición del sujeto decadente que celebra su indefinición sexual: "resulta prácticamente demostrable, sin dar lugar a ninguna duda, que la humanidad va perdiendo en equilibrio fisiológico y en virilidad y energía de carácter, todo lo que en el orden moral gana como progreso efectivo" (150). Según este razonamiento, los atributos de género devienen elementos móviles, rasgos inestables que no pertenecen al inmutable terreno de los cuerpos biológicos. De hecho, al entender la feminidad como experiencia estética, ésta se desliga de cualquier atribución genital o esencial que podría otorgarle el discurso científico. Así, de Oscar Wilde afirmará que "la Belleza no tenía ninguna culpa de que [...] fuese un cerebro femenino con cuerpo de varón” (161). También volverá a aludir a esta feminización al señalar "las condiciones del espíritu moderno, artista con delicadezas de hembra y con caprichos de refinado" (109), y de igual modo describirá a los artistas contemporáneos como aquellos en “quienes la herencia, la educación y el medio, han dado caracteres anímicos no muy en consonancia con su sexo. Son almas que lo sienten todo a lo mujer" (150). Así, aunque la mujer es expulsada del territorio de la creación artística, configurándola como objeto de contemplación o inspiración, en contrapartida, la masculinidad se desplaza hacia la androginia. A pesar de reproducir el paradigma de degeneración y feminización habitual, éste no se presenta como una cuestión negativa. Más bien al contrario, indica que esa pérdida de virilidad se resuelve en progreso.

A pesar de reivindicar a los hombres que no corresponden a su sexo, la feminidad va aparecer en el ensayo de forma dual, disociada entre una 
elaboración artística y la mujer como un individuo atávico. En un primer momento, se la describe como un sujeto atrasado, ubicándola en una posición de inferioridad evolutiva respecto al hombre: "como la hembra es un ser incompleto o que se comporta al menos como tal, necesita ver siempre en el hombre una superioridad de cualquier orden y sin mezcla, para quererle y desear complementarse a sus expensas" (151). Frente a esta concepción ortodoxa, el texto desarrollará una descripción mucho más ambigua de la feminidad ${ }^{9}$, que se entiende como una de las escalas del arte, motor de la creación y a su vez fruto de la misma. Aunque insistirá en mantener a la "hembra" en el espacio de la disquisición científica, el aragonés complica el panorama, al entender también la feminidad como un arte: "Existen dos artes, que no acostumbran a ser consideradas como tales; derivación tal vez una de otra, pero que el hombre diferencia y distingue instintivamente, conociéndolas como dos maneras distintas de manifestarse lo bello; el arte de lo natural y el de la feminidad; sus obras son la Naturaleza y la mujer” (10). Esta división va a propiciar que $A C$ se mueva en un precario equilibrio retórico entre la perspectiva científica más ortodoxa y el género como tropo artístico totalmente opuesto al esencialismo biológico. Así, el género se va a desligar de su dimensión absoluta para configurarse desde la subjetividad individual y el ámbito estético.

Este paradigma de rechazo a la mujer se constituye en la quintaesencia del sujeto decadente, que rechaza todo lo que tenga que ver con lo natural. En el que se considera el breviario decadentista por excelencia, À rebours, de Joris Karl Huysmans, la carencia de su protagonista Des Esseintes por la artificialidad excluía de sus intereses a las mujeres, como elementos asociados a una naturaleza caracterizada por imágenes de volubilidad, irracionalidad y reproducción (Dijkstra). La teoría de Llanas se sitúa también en la preferencia del decadentismo, no solo hacia una estética, sino hacia una identidad alejada de lo natural. Así, la mujer solo puede presentarse como un ideal abstracto, fruto del refinamiento moderno y a la altura de las mejores obras artísticas: "El cuadro, la música, la poesía, nos hacen vivir una vida especial, activa y exaltada; la mujer eleva esa vida en grado sumo; nunca la emoción musical

9 Esta dicotomía resulta recurrente en el fin de siglo, sobre todo en el ámbito de la producción artística: "femininity is now appropiated by the male artist as emblematic of the modern" (Felski, "The Counterdiscourse of the Feminine" 1095). Véase también BuciGlucksmann y Kirkpatrick (Mujer, modernismo y vanguardia). 
ni la poética, y eso que son artes superiores, llegarán a hacernos sentir en cien años de vida lo que una mujer puede hacernos sentir en media hora" (210).

La voz decadente que asoma en $A C$ traza un sujeto enfermo, que desafía las retóricas de poder de los discursos médicos al reivindicar la neurosis como un signo de la modernidad. De igual modo, ese mismo personaje, productor y receptor ideal del emotivismo, aparece como una masculinidad desvirilizada, que colapsa también el rígido binarismo del género anatómico. La insistencia, sin embargo, en reservar un espacio para la "mujer" o la "hembra” apunta a un panorama paradójico, en el que la deconstrucción de las identidades convive con la reproducción de sus límites más férreos.

Esta doble reescritura -de la enfermedad y el género-plantea una subversión ideológica de los modelos de conocimiento en torno a la cultura, los cuerpos y los sujetos, de un modo similar al que hará Rafael Urbano en su Manual del perfecto enfermo. Asimismo, en los diez años que separan ambos textos, muchos de los elementos que en $A C$ se discuten -a menudo con un exceso de ambigüedad y cautela-, se darán por sentados en el ensayo de Urbano. Es decir, que las revisiones en torno a lo patológico y la lectoescritura que se esbozan en el texto de Llanas volverán a reaparecer en el Manual, apuntando a un imaginario finisecular que se extiende y se asienta en las primeras décadas del siglo XX.

\section{TÚ ENFERMO SANO, Y YO MÉDICO YERTO: EL MANUAL DEL PERFECTO ENFERMO}

Al igual que Llanas Aguilaniedo, Rafael Urbano (Madrid, 1870-1924) se sitúa en esa categoría de escritores catalogados como raros y menores, o directamente olvidados por la historiografía literaria. Estos olvidos contrastan, sin embargo, con su polifacética y amplia producción, que, como viene siendo habitual en el fin de siglo, oscila entre campos tan variopintos como el socialismo, el anarquismo y el ocultismo. Además de trabajar como periodista en numerosos medios publicó ensayos sobre cuestiones tan variadas como una Historia del socialismo (1903) y temas ocultistas en El sello de Salomón (un regalo de los dioses) (1907) y El diablo: su vida y su poder, toda su historia y vicisitudes (1922). En cuanto a producción literaria, publica los poemas Tristitia seculae: soliloquios del alma (1900) y novelas como La sante fe (1909) y Más fuerte que el amor (1927). Fue, además, un prolífico traductor de autores clásicos, como Rousseau o Platón, y contemporáneos, como D’Annunzio, Strindberg, 
Nietzsche y Madame Blavatsky ${ }^{10}$. Este perfil, entre la teosofía, el socialismo y incluso el humorismo que aparece en algunas páginas del Manual, resulta relevante, igual que en el caso de Llanas, a la hora de abordar el trabajo que nos ocupa. Del mismo modo que el autor aragonés, en su biografía y en su obra se desplaza desde el positivismo científico de su época de estudiante de Farmacia al modernismo estético, el perfil ecléctico de Urbano desvela lo que parece una constante del fin de siglo: la profunda interrelación entre posiciones ideológicas excéntricas que, de un modo u otro, desarticulan el positivismo científico como elemento insertado en las estructuras de poder contemporáneas. En otras palabras, no parece casual que la preocupación por lo espiritual más allá del catolicismo ortodoxo se una, por ejemplo, a la militancia socialista, junto con una producción escrita que tiende a poner en duda las verdades esenciales de las ciencias, especialmente las médicas y psiquiátricas.

El Manual del perfecto enfermo está formado por un conjunto de conferencias que el polifacético escritor dio en el Ateneo de Madrid el 3, 10 y 17 de diciembre de 1910, y que serían publicadas al año siguiente, con diversos prólogos y dos apéndices añadidos por el autor. Los tres capítulos que componen el volumen tratan diversos aspectos culturales de la enfermedad, bajo los títulos de "El arte de quejarse”, "En la vía doliente” y "La dirección orgánica”. El propósito general del ensayo es, según el propio Urbano, ofrecer "un libro para el lector convaleciente de otras lecturas" (29). Es decir, como el arte terapéutico que defiende Llanas, el MDPE también se presenta con una función curativa para un lector idealmente enfermo: "estas tres conferencias han sido concebidas para ofrecerse idealmente a un público menos sano que vosotros" (1911: 35).

Asimismo, el texto viene precedido de diversos prólogos firmados por personalidades políticas, literarias y médicas que elogian la obra y animan a su lectura. El Dr. Isaac Moreno firma por ejemplo una "Licencia" en la que

10 Se ofrece en el Diccionario Espasa de Literatura Española esta breve reseña biográfica: "Ensayista. Periodista en provincias desde muy joven, en 1895 se trasladó a Madrid después de conseguir un puesto en el Ministerio de Instrucción Pública. Hombre muy culto, colaborador de numerosos diarios y célebre conferenciante en el Ateneo de Madrid, al final de su vida se interesó por las ciencias ocultas" (Bregante 991). Apenas he encontrado menciones a su figura en Sobejano $(75-77,470)$ y Allegra (386-420). Baroja también hace una mención en Galería de tipos de época (Obras completas 838) en la sección dedicada a los escritores bohemios y políticos. 
señala que el ensayo hará "reír y pensar al más neurasténico" (Moreno 6). En línea con ese lector enfermo al que se dirige el texto, otros prologuistas van a destacar, directamente, la dimensión higiénica de la obra, que "reúne las condiciones de sanidad e higiene, tanto morales como materiales, que la ciencia recomienda" (Barcones 8). Por su parte, Cristóbal de Castro introduce la que será una constante -y problemática- idea en el manual, referida a la borrosa frontera entre salud y enfermedad: "Entrambos pasaremos a la Historia/ tú Enfermo sano, y yo Médico yerto" (De Castro 10). Ambos versos podrían pasar desapercibidos como una mera ironía en torno a la temática del volumen si no fuese porque Urbano va a volver sobre esta dicotomía para analizarla a fondo y mostrar lo relativo de ambas categorías. El oxímoron que forman el "enfermo sano" y el "médico yerto" puede entenderse a partir de un marco de crisis en torno al esencialismo de dichos conceptos. De este modo, el discurso médico dejará de configurarse como la máxima autoridad sobre los cuerpos y el enfermo pasará a ocupar un papel muy distinto al de una mera superficie de inscripción de la mirada científica.

De entre todos estos paratextos destaca el de José Francos Rodríguez, escritor, médico y alcalde de Madrid en dos ocasiones (entre 1910-1912 y 1917-1919), que anuncia una de las ideas cabales del ensayo, al afirmar que "cada enfermo es un actor que representa a su manera el papel” (Francos 19). Urbano retomará esta idea para indicarle al lector cómo debe realizar su representación en aras de facilitar la tarea del médico. El perfecto enfermo del título se construye así en una serie de gestos repetidos que pueden entenderse desde los parámetros de performatividad que Judith Butler adscribía al género, constituido a partir de la ilusión de una fijeza interior (103). Sin embargo, aunque por un lado se reconoce la dimensión performativa de lo patológico, por otro se recomendará al enfermo una actuación correcta, que lo identifique con un sujeto dócil que acata diagnóstico y tratamiento correspondientes. Básicamente, lo que va a pedir Urbano será a un buen actor de su dolencia, cuya representación se ajuste a lo que el discurso médico espera de sus pacientes.

El MDPE se presenta como un texto comprometido con las amenazas colectivas de las que se ocupa el higienismo, claro referente intertextual. Parte así de la premisa, ratificada por el alcalde de Madrid, de que "todos, cual más, cual menos, estamos enfermos" (Francos 19). Este paradigma se manifiesta, por ejemplo, en la necesidad de formación médica que según Urbano debería tener la clase política (40) y en la poco novedosa comparación de los médicos con directores espirituales (66). A pesar de esta insistencia, el ensayo se va a centrar en el enfermo, cuya misión es facilitar el camino 
a los doctores y realizar la representación más adecuada de su patología en cada momento.

Dentro de los recursos ofrecidos para esa representación de la enfermedad, destaca el modo de confesión. Urbano, de hecho, ofrece un curso de narrativa rápida al precisar la manera en que el enfermo debe adoptar la retórica despersonalizada y en apariencia objetiva del caso clínico:

Todos los preceptos confesionales pueden llenarse cumplidamente si referimos nuestros hechos como si fueran ajenos, despersonalizándolos en lo posible y refiriéndolos con un descuido que facilite la psicología sobre ellos, que debe hacer el doctor. La falta de retórica en el relato del caso, es la condición más necesaria para obtener la salud y la absolución (69).

Además de la equivalencia entre la absolución del pecado y la salud como redención moderna, cabe destacar la posición objetiva con la cual el enfermo debe narrarse a sí mismo, siendo en cambio el doctor quien aplica la psicología sobre cada caso. Aunque su propósito resulta inicialmente disciplinario -un enfermo dócil, que encarna el ideal retórico del caso clínico-, esta propuesta socava la distinción que sitúa la mirada médica en el territorio de la objetividad universal y atribuye al discurso del enfermo una subjetividad particular. Urbano invierte este modelo, ya que retrata al enfermo contemplándose a sí mismo con la imparcialidad en principio asignada al médico: de ahí la insistencia en el modo de narrar, que se constituye como la vía principal de despersonalización del yo.

En un contexto de tensión entre los modos de escritura y la crisis del discurso científico, ejemplificada en los debates que se recogían en $A C$, la insistencia en esta cuestión me parece significativa, más cuando la retórica defendida para el enfermo se corresponde con el modelo realista-naturalista que también toma para sí el discurso médico. El texto muestra así la preocupación generalizada por los modos de narrar el cuerpo y la identidad, así como la interrelación entre narrativa y discurso médico: la medicina se articula así como un texto marcado por unas convenciones narrativas muy específicas, que el enfermo debe reproducir ${ }^{11}$. Urbano, además, apunta hacia un lugar de enunciación imposible, en el que el narrador objetivo del caso clínico es el propio enfermo en vez del médico. De este modo, una narración adecuada 
del yo supone el primer paso para convertirse en el perfecto enfermo que pretende configurar el texto.

Igual que las detalladas instrucciones respecto a la confesión ponen en evidencia la dimensión narrativa de la enfermedad, los temores en torno a la omnipresencia de lo patológico pronto se desvinculan del modelo de conocimiento higienista para acercarse a otro tipo de preocupaciones, fruto de la crisis finisecular en torno al sujeto. Pasamos, por lo tanto, de la amenaza patológica del sujeto degenerado a un diagnóstico de sufrimiento transversal: "puede definirse el mundo como un nosocomio universal. Todo sufre, llora, padece; todo está lleno de dolor. Hay enfermedades y enrarecimientos para todas las vidas y para todos los cuerpos [...]. La universalidad de la dolencia y la enfermedad ataca a todos los órdenes" (39).

Cercano a las teorías anarquistas de Sebastian Faure en Le doleur universelle, Urbano se distancia de la retórica del discurso médico para articular un concepto de patología mucho más problemático, que se anunciaba en el prólogo de Francos Rodríguez: "nuestro dolor no es una adquisición del momento, ni nuestra enfermedad la hemos atrapado ayer o antes de ayer al entrar y salir de cualquier parte. Es una cosa ingénita y connatural con nosotros" (41). Estas afirmaciones sobre el dolor y la enfermedad como un mal universal se desligan en los pasajes citados de su dimensión médico-higienista, para convertirse en una cuestión vinculada a la identidad moderna: "El dolor universal no era la suma de mil dolores individuales: era el dolor de toda una época que surgía en el ocaso de las grandes civilizaciones e imprimía un particular pathos colectivo, visible en las manifestaciones estéticas e intelectuales" (Calvo 199).

Esta relación de la enfermedad y el dolor con lo estético no es una cuestión aislada, sino que había sido tema común en la última década. Pío Baroja, por ejemplo, realizaría una tesis doctoral en Medicina que fue presentada en 1896 bajo el título de El dolor. Un estudio de psicofísica. Tanto Baroja como Urbano comparten la idea de que el dolor deviene un impulso creativo que mueve el progreso científico y estético. Así, Urbano lo define como "lo más progresista y civilizador que se conoce" (41), y más adelante apunta que "la equivocación de considerar el dolor como algo negativo, como algo que no es nuestro ni natural, nos lleva a errores mayores en todos los órdenes de la vida" (52). Por su parte, Baroja también indicaba unos años antes esa misma relación: "el dolor es duradero y aporta un conocimiento [...]. Si nos fijamos en la fisonomía del hombre que sufre, veremos que a la que más se parece es 
a la fisonomía de hombre que piensa. [...] El dolor da la idea clara y distinta de lo que somos" (El dolor 8).

Si para Baroja y Urbano el dolor supone conocimiento, y a su vez el conocimiento deriva en dolor, resulta fácil trazar las relaciones textuales de ambas propuestas con los artistas enfermos de $A C$, "poco más que desechos humanos desde un punto de vista de la eugenesia, motores del progreso desde el punto de vista del arte" (Pitarch 8). Sin embargo, mientras Llanas se sitúa en el terreno de la estética, Urbano insistirá en el dolor y la enfermedad como motores, también, del progreso científico. Lo patológico ya no se opone a un ideal normativo de salud, sino que se presenta como un espacio para la escritura y la investigación científica que supera la pasividad habitual asignada al cuerpo enfermo.

\subsection{LA REDEFINICIÓN DE LO PATOLÓGICO}

En este contexto, Urbano, al igual que Llanas, va a diferenciar entre diversos estratos de la enfermedad, planteando una reescritura muy particular del degenerado superior en función de los distintos grupos sociales. Así, en $A C$ se insinuaba una patología constituida a partir de la división entre intelectuales y obreros como dos grupos enfermos. Urbano, cuyas simpatías hacia el anarquismo y el socialismo eran mucho más declaradas, desarrolla una idea similar, en la que se atomiza la enfermedad, paradójicamente, para mantener su cualidad transversal:

Si no se quiere destruir este concepto de unidad con que se ofrece la patología, entonces habrá que exponerla por estratos y capas sociales, reservando para las clases más retrasadas las alteraciones en los aparatos terminales de sentido y en la parte periférica del cuerpo, y consagrando de manera exclusiva la patología cerebral para las clases más cultas y superiores (118).

A pesar de la unidad que dice mantener el autor, la estratificación social de la enfermedad apunta hacia otro tipo de premisas. Urbano reproduce el recurrente modelo según el cual el enfermo de las clases más elevadas adolece de patologías nerviosas, y el de la clase obrera es retratado, al estilo lombrosiano, como un ser atávico y evolutivamente inferior. El autor se va a centrar además en un grupo muy específico de las patologías cerebrales de las clases cultas, cuyos ecos remiten, a mi juicio, al lector enfermo del emotivismo: "El intelectualismo es una enfermedad, y una enfermedad grave, 
superaguda, si es que puedo emplear esta palabra para indicar lo superlativo del mal. Es una enfermedad que pertenece a la patología de una raza artificial o voluntariamente escogida" (123).

Estas afirmaciones conducen de nuevo al perfil que trazaba Llanas, a partir de la psiquiatría, al relacionar enfermedad y exceso de actividad mental. Sin embargo, al introducir los conceptos de artificialidad y elección individual, el texto colapsa los modelos más ortodoxos de patologización, para acercarse a una reelaboración de la enfermedad como tecnología del yo o incluso una performance. El cuerpo enfermo deja de ser una superficie pasiva, afectada por una lesión y sometida a escrutinio médico, para convertirse en una cuestión cultural determinada a menudo por el propio sujeto, al margen de las leyes naturalistas del medio y la herencia: "es un padecimiento vicioso que, como todos los de esa índole, no se deben a la herencia, sino a la libre adquisición personal del enfermo" (126-127). Esta reescritura de las categorías patológicas convive sin embargo con la cientificidad que impregna el texto, que acude al caso clínico como prueba de verdad irrefutable: "poseo en la actualidad sesenta y siete historias clínicas, que tengo catalogadas como las fichas de un registro de policía. He conocido y tratado personalmente a todos mis enfermos y he procurado aliviarlos en ocasiones - dos muy notables, por cierto-, pero sin lograr éxito alguno" (123-125).

La voluntad disciplinaria del texto toma forma en la mención del archivo: la colección de casos, organizados en fichas y a menudo acompañados de una fotografía, deviene uno de los grandes dispositivos de control colectivo en el siglo XIX ${ }^{12}$. Esta recopilación, que aunque no sea un archivo institucionalizado, aquí funciona como tal, sobrepasa sin embargo sus propósitos de control. En primer lugar, porque Urbano reconocerá su escaso éxito en cuanto a logros terapéuticos: el caso clínico como acto de narrar el cuerpo no deriva en la curación, ni siquiera en un dispositivo de control efectivo, sino simplemente en la escritura, puesto que el objetivo del manual es el de crear buenos enfermos, y no individuos sanos.

Otro punto fundamental que enlaza ambos ensayos tiene que ver, como he señalado ya, con la relación entre escritura y patología. Urbano ya anunciaba

12 Véase Sekula, que señala la doble dimensión simbólica y estructural del archivo: "In structural terms, the archive is both an abstract paradigmatic entity and a concrete institution. In both senses, the archive is a vast substitution set, providing, for a relation of general equivalence between images" (17). 
al principio que su ensayo iba dirigido al enfermo convaleciente de las malas lecturas: "vicioso de un vicio nuevo [...], ni sano ni enfermo de verdad, estás a buen seguro convaleciente del terrible mal de leer, mal que ha concluido con la funesta manía de pensar" (28). Igual que en $A C$, se trata de un discurso obsesionado con la lectoescritura como síntoma y causa de toda clase de enfermedades. Así, mientras Llanas plantea su propuesta emotivista como terapia, el Manual de Urbano también se legitima como una más que probable lectura higiénica para el enfermo. No obstante, nótese que ni el aragonés ni el madrileño especifican exactamente un propósito curativo: aunque Llanas plantea un trasfondo regeneracionista, su propuesta literaria se emplaza en la exploración de la emoción y el marco de la decadencia, dejando de lado el insinuado renacimiento de las artes y los sujetos. Urbano, por su parte, plantea un manual de conducta en vistas a una posible curación, pero centrándose, sin embargo, en el enfermo y su representación de la enfermedad, de cara a ofrecer, como Llanas, solo un alivio momentáneo: "No quiero que dejes de leer, enviciado lector, pero sí proporcionarte un paréntesis en tus lecturas; así, para tu recreo y tu descanso ha sido concebido este libro" (30). A pesar de identificarse con la verdad de la enunciación científica, ambos textos realizan una desarticulación de los discursos médicos, convirtiendo la enfermedad en una categoría identitaria que se perfila como el principal terreno de reflexión.

\subsection{EL ENFERMO EN MASCULINO}

Igual que $A C$, el perfil que traza Urbano se constituye desde una masculinidad implícita: mientras Llanas saca a la luz esta cuestión con sus reflexiones en torno a la feminización del enfermo y la mujer como creación artística, Urbano ni siquiera hará mención al tema. Los silencios, no obstante, pueden ser igual de significativos que las alusiones directas: la configuración del perfecto enfermo irá, en ese sentido, destinado a resituar la performance de lo patológico en el terreno de una masculinidad problemática.

Parece evidente que el MDPE incorpora una serie de preocupaciones vinculadas a las crisis de fin de siglo como la patologización colectiva e individual y la enfermedad como una cuestión cultural que colapsan las pretensiones médicas del texto. No es de extrañar por lo tanto, que el enfermo de Llanas y Urbano esté marcado en un masculino demasiado sospechoso para entenderlo desde parámetros universales e inclusivos. Sin embargo, mientras que en $A C$ queda especificado, el sujeto del $M D P E$ resulta mucho más sutil. 
En primer lugar, me parece llamativa la relación del enfermo de Urbano con un exceso de lecturas, siendo ésta una cuestión femenina de larga tradición en el siglo XIX (Simón, Hibbs-Lissorgues). Es más, el sujeto que se perfila en el Manual está afectado de bovarismo: “Mr. Julio Gautier ha estudiado en Francia la variedad genuinamente francesa de esta dolencia, bajo el nombre de bovarismo, que ha definido como 'la facultad conferida al hombre de imaginarse otro que no es"' (132). Resulta evidente que el modelo de mala lectora que encarna Emma Bovary -y que en España ejemplificaría la galdosiana Isidora Rufete en La desheredada- apunta a la mujer como un sujeto lector que tiende a la subjetividad, la interpretación errónea y la confusión de la realidad con la ficción ${ }^{13}$. Sin embargo, Urbano construye a ese lector en masculino, asumiendo además la vinculación entre actividad mental, lectura y patología que se exploraba también en $A C$.

En segundo lugar, las recomendaciones que dará el $M D P E$ vienen a configurarse en una serie de metáforas de género que vale la pena analizar. He referido anteriormente la insistencia en la manera de realizar una confesión ante el médico, que además debe seguir el modelo retórico del realismo-naturalismo basado en la objetividad y el desapasionamiento: "la personalidad en el relato ha creado una multitud de enfermedades que en realidad no existen, y sobre las cuales todo diagnóstico y tratamiento son absolutamente imposibles" (69). No hay que olvidar, en ese sentido, que los modos de narrar se construyen también a través de las metáforas de género que durante todo el siglo XIX habían caracterizado el realismo y el naturalismo con marcas masculinas, situando el lirismo y la subjetividad en el volátil terreno de narrativas consideradas "femeninas" (Kirkpatrick "Gender and Diffeence”, Blanco, Jagoe “Disinheriting the Feminine”). Así, Urbano plantea otra vuelta de tuerca al contexto de feminización de la cultura en el que se inserta: ya no se trata solo de producciones artísticas, sino que la confesión ante el médico también debe realizarse a través de una objetividad entendida en términos de virilidad. No es de extrañar, por lo tanto, que a la mujer le sea difícil acceder a esos niveles de despersonalización del propio yo. Al fin

13 Aunque Jules de Gaultier, en el volumen Le Bovarysme, la psychologie dans l'œuvre de Flaubert, emplea el término para analizar la patología de diversos personajes del escritor francés, e incluso como un modo de entender lo real, tampoco lo especifica como una afección específicamente femenina. 
y al cabo, si es incapaz de realizar tales hazañas en el mundo de la creación artística, mucho menos podrá emularlas ante el médico.

Otra de las cuestiones a las que más atención se presta tiene que ver con la queja y la expresión del dolor, estableciendo todo un protocolo que marca el comportamiento de la vida doliente:

No se debe gritar demasiado; hay que moderarse en lo posible para no descomponer nuestro continente y perjudicarnos con una acción inútil. [...] Un grito agudo, cuando el dolor es fuerte, está completamente justificado y hasta debe darse poniendo la intención de arrojar el dolor al exhalarlo; mas no debe hacerse, es intolerable, contagioso y como tal revertible al punto de partida. [...] Una consideración sobre la dolencia, el trazado mental del perímetro del dolor y el esfuerzo por reducirlo todo lo posible, serían más convenientes y provechosos que esos gritos desacompasados que desasosiegan el ánimo, agradan la jurisdicción morbosa e infestan el sistema nervioso (55).

Lo patológico se sostiene, de este modo, sobre una representación para la cual el texto ofrece cuidadosas indicaciones. Si la intensidad de la performance puede afectar a la "jurisdicción morbosa”, Urbano da a entender que es la actitud exterior, basada en la queja y el grito, aquello que constituye la interioridad biológica. Sin embargo, en lugar de resaltar la artificialidad de lo patológico como pose -a menudo transgresora (Molloy)- el texto propone un cuerpo que no ponga en evidencia esa performatividad, al recomendar la eliminación de toda gestualidad exagerada que pueda traer consigo la enfermedad.

La crítica al exceso de quejas y gritos apunta, además, al modelo de dramatización de la histeria, cargado de gestos y exclamaciones totalmente dramatizados. En este sentido, la propuesta de Urbano viene a eliminar las marcas femeninas de lo patológico, que son las que además ponen en evidencia su dimensión teatral ${ }^{14}$. La enfermedad se configura así como una representación que pretende renunciar a la personalización y la ornamentación, quedando así

14 La relación entre histeria y teatralidad es una constante desde la actualización de esta dolencia que realiza la medicina decimonónica, como una enfermedad femenina basada en la imitación de otros síntomas. Esta dimensión performativa se vería acentuada gracias a las teorías de Jean Martin Charcot, que trataba a las histéricas con hipnosis y les hacía representar, en sesiones públicas, diversos papeles. Hacia finales de siglo la histeria había ya traspasado las fronteras especializadas, y su modelo de corporalidad se reproducía en teatros y espectáculos populares de diversa índole. Véanse los trabajos de Clúa y Gordon al respecto. 
asociada a narrativas marcadas en masculino. La simulación, la actuación y la subjetividad, quedan por lo tanto en el lado de la feminidad, excluida del perfecto enfermo que propugna el texto. Al realizar este desplazamiento, el $M D P E$ procura en cambio virilizar lo patológico, eliminando todas aquellas marcas de género asociadas a la neurosis. Así, recomendará una suerte de impasibilidad igual de conflictiva que la confesión narrada desde fuera de uno mismo: "la ataraxia o impasibilidad que predicaban los estoicos, no era tanto una enseñanza moral como una enseñanza estética, estética, sí; pero llena de verdadera salud y sanidad, como toda la obra bella, cualesquiera que sea su presentación externa y el medio donde se revele" (54). En primer lugar, cabe recordar que el término "ataraxia” ha sido asociado a un noventayochismo cuya impasibilidad se oponía, en apariencia, a las feminizadas neurosis modernistas. Sin embargo, se ha señalado ya que esta actitud forma parte del imaginario emocional y de la neurosis finisecular que atacaba a casi todos los escritores e intelectuales del momento (Blasco 66).

En segundo lugar, la alusión a una actitud estética no me parece aquí nada casual: en un contexto que abarca ya más de una década de ismos finiseculares, Urbano da por hecha la relación entre enfermedad y representación, a pesar de que la intente trasladar desde la artificiosidad hacia la despersonalización. Sin embargo, el texto asume lo patológico como un tipo de subjetividad que el enfermo debe, al menos, disimular. Esto explicaría las metáforas de masculinidad que acompañan al retrato del probable lector, ya que, por su naturaleza inestable, la mujer no puede situarse en el marco del sujeto que busca configurar el Manual: la referencia a la ataraxia, de este modo, excluye a la mujer como posible participante de esta modernidad patológica y productiva.

\section{CONCLUSIONES}

Si bien la relación entre masculinidad y patología que establecen ambos textos socava el binomio de la mujer como potencial enferma y traza una masculinidad que deconstruye los modelos hegemónicos, ese vínculo eleva lo patológico al territorio privilegiado y excluyente de la actividad mental, el progreso científico o la creación artística. Así, mientras que $A C$ pone en evidencia la feminización y patologización del sujeto y de la escritura, el MNDP intenta resituar la enfermedad en un enunciador objetivo e implícitamente masculino. Sin embargo, ambos textos dan cuenta de un mismo fenómeno, en el que se presupone al hombre -más o menos enfermo, más o menos viril-, 
como el artista y el intelectual por excelencia. A su vez, este proceso supone una revisión de categorías esenciales que marcan el discurso científico como las de género o enfermedad, que se revelan como construcciones culturales, metáforas, creaciones artísticas y ficciones de la identidad. Ambos textos, así como el período que abarcan, pueden considerarse no solo sintomáticos, sino claves para abordar el imaginario cultural del fin de siglo en España. Frente a atomizaciones excesivas de movimientos literarios, Llanas y Urbano muestran la unidad de un cambio de siglo caracterizado por las ansiedades del poder en torno a los modos de narrar la subjetividad.

\section{BIBLIOGRAFÍA}

Allegra, Giovanni. "Ermete modernista: occultisti e teosofisti in Spagna, tra fine ottocento e primo novecento". Annali Dell'Istituto Universitario Orientale. Sezione Romanza 21.2 (1979): 357-415.

Ara, Juan Carlos. "El alma contemporánea de Alma contemporánea, claves ideológicas para un libro y un cambio de siglo”. Alazet: Revista de Filología 2 (1990): 9-54.

Armus, Diego. "La enfermedad en la historiografía de América Latina moderna”. Asclepio: Revista de Historia de la Medicina y de la Ciencia 54/2 (2002): 41-60.

Armus, Diego, ed. Entre médicos y curanderos. Cultura, historia y enfermedad en la América Latina moderna. Buenos Aires: Norma, 2002.

Disease in the History of Modern Latin America. From Malaria to AIDS. Durham: Duke University Press, 2003.

Barcones, Enrique Mateo. “Censura e informe médico del libro”. Manual del perfecto enfermo. Rafael Urbano. Madrid: Librería de Francisco Beltrán, 1911. 7-8.

Baroja, Pío. Obras completas. Tomo 7. Madrid: Biblioteca Nueva, 1949.

El dolor: estudio de psico-física. Ed. Luis S. Granjel, Salamanca: Real Academia de Medicina de Salamanca, 1980.

Bernheimer, Charles. Decadent Subjects: The Idea of Decadence in Art, Literature, Philosophy, and Culture of the Fin de Siècle in Europe. Baltimore: The John Hopkins UP, 2002.

Blanco, Alda. "Gender and National Identity: The Novel in Nineteenth-Century Spanish Literary History”. Culture and Gender in Nineteenth-Century Spain. Ed. Lou CharnonDeutsch y Jo Labanyi. Oxford: Oxford UP, 1995. 120-136.

Blasco, Javier. “De 'oráculos' y de 'cenicientas': la crítica ante el fin de siglo español”. ¿Qué es el modernismo? Nueva encuesta, nuevas lecturas. Ed. Richard Cardwell y Bernard McGuirk. Boulder, Colorado: Society of Spanish and Spanish-American Studies, 1993. 59-86.

Bono, James. "Science, Discourse, and Literature: The Role/Rule of Metaphor in Science”. Literature and Science. Theory \& Practice. Ed. Stuart Peterfreund. Boston: Northeastern UP, 1990. 59-89. 
Bregante, Jesús. Diccionario Espasa de literatura española. Madrid: Espasa Calpe, 2003.

Broto, Justo. Un olvidado: José María Llanas Aguilaniedo. Huesca: Instituto de Estudios Altoaragoneses, 1992.

Buci-Glucksmann, Christine. "Catastrophic Utopia: The Feminine as Allegory of the Modern”. The Making of the Modern Body: Sexuality and Society in the Nineteenth Century. Ed. Catherine Gallagher y Thomas Laqueur. Berkeley: California UP, 1987. 220-229.

Butler, Judith. El género en disputa: el feminismo y la subversión de la identidad. Barcelona, Buenos Aires, México DF: Paidós, 2001.

Campos, Ricardo, et al. Los ilegales de la naturaleza. Medicina y degeneracionismo en la España de la Restauración (1876-1923). Madrid: CSIC, 2000.

Calvo, José Luis. “Alma contemporánea: una estética de la modernidad”. Castilla: Revista de Estudios de Literatura 15 (1990): 33-52.

Cardwell, Richard. "Médicos chiflados: medicina y literatura en la España de fin de siglo". Siglo Diecinueve 1 (1995): 91-116.

Clúa, Isabel. "El cuerpo como escenario: actrices y histéricas en el fin de siècle”. Dossiers Feministes 10 (2007): 157-172.

De Castro, Cristóbal. “Del Médico furioso al Perfecto enfermo”. Manual del perfecto enfermo. Rafael Urbano. Madrid: Librería de Francisco Beltrán, 1911. 11.

Del Pozo, Alba. “¿Tienen alma las plantas? El colapso de la ciencia y el modernismo fin de siglo en los artículos de José María Llanas Aguilaniedo”, Individuo y sociedad en la literatura del XIX, Ed. Borja Rodríguez y Raquel Gutiérrez. Santander: Tremontorio, 435-448.

Dijkstra, Bram. Idols of Perversity: Fantasies of Feminine Evil in Fin-de-siècle Culture. Oxford, New York: Oxford UP, 1986.

Felski, Rita. "The Counterdiscourse of the Feminine in Three Texts by Wilde, Huysmans, and Sacher-Masoch”. Publications of the Modern Language Association 106.5 (1991): 1094-1105.

Fillière, Carole. "Esthétique d'un autre Modernisme: 1"emotivismo' de José María Llanas Aguilaniedo”, Le socle et la lézarde en Espagne contemporaine, Ed. Serge Salaün. Paris: Centre de Recherche sur l'Espagne Contemporaine, Université Paris 3, 2010. 224-287. http://crec.univ-paris3.fr/lezarde/Ancien\%20et\%20nouveau1.pdf.

Foucault, Michel. Tecnologías del yo y otros textos afines. Barcelona, Buenos Aires, México DF: Paidós, Universitat Autònoma de Barcelona, 1990.

Francos, José. "Prólogo. El arte de padecer”, Manual del perfecto enfermo. Rafael Urbano. Madrid: Librería de Francisco Beltrán, 1911. 17-26.

Gilman, Sander. Disease and Representation. Images of Illnes from Madness to AIDS. Ithaca, London: Cornell University Press, 1988.

Gordon, Rae Beth. Dances with Darwin, 1875-1910. Vernacular Modernity in France. Farnham, Burlington: Ashgate Publishing, 2009.

Huertas, Rafael. Locura y degeneración: psiquiatría y sociedad en el positivismo francés. Madrid: CSIC, 1987.

Los laboratorios de la norma. Medicina y regulación social en el estado liberal. Madrid: CSIC, Octaedro, 2008. 
Historia cultural de la psiquiatría: (re) pensar la locura. Madrid: La Catarata, 2012.

Hibbs-Lissorgues, Solange. "Femmes et lectures au XIXe siècle en Espagne: doctrines et pratiques”, La question du lecteur. Actes du XXXIe congrès de la Société des hispanistes français (Marne-la-Vallée, 16-17-18 mai 2001). Dir. Louise Bénat-Tachot y Jean Vilar. Marne-la-Vallée: Presses Universitaires, Ambassade d'Espagne, 2004. 191-208.

Jagoe, Catherine. "Disinhereting the Feminine: Galdós and the Rise of the Realist Novel in Spain”. Revista de Estudios Hispánicos 27 (1993): 225-248.

“Sexo y género en la medicina del siglo XIX”. La mujer en los discursos de género: textos y contextos en el siglo XIX. Ed. Alda Blanco, et al. Barcelona: Icaria, 1998. 305-367.

Jordanova, Ludmilla. Sexual Visions: Images of Gender in Science and Medicine between the Eighteenth and Twentieth Centuries. Wisconsin: Wisconsin UP, 1989.

Kirkpatrick, Susan. “Gender and Difference in Fin de siglo Literary Discourse”. Spain Today: Essays on Literature, Culture, Society. Ed. José Colmeiro, et al. Hanover: Darthmouth College, 1995. 95-101.

Mujer, modernismo y vanguardia en España (1898-1931). Madrid: Cátedra, 2003.

Llanas, José Ma . Alma contemporánea: estudio de estética [1899]. Ed. Justo Broto. Huesca: Instituto de Estudios Altoaragoneses, 1991.

Litvak, Lily. España 1900. Modernismo, anarquismo y fin de siglo. Barcelona: Anthropos, 1990.

Lombroso, Cesare. L'uomo di genio in rapporto alla psichiatria, alla storia ed all'estetica. Torino: Fratelli Brocca, 1894.

Magnan, Valentin y Paul-Maurice Legrain. Les dégénérés (état mental et syndromes épisodiques). Paris: Rueff et Cie, 1895.

Magnan, Valentin. Leçons cliniques sus les maladies mentales faites a l'Asile Clinique (SainteAnne). Paris: Progrès Medicale, 1897.

Molloy, Sylvia. "The Politics of Posing. Translating Decadence in Fin-de-Siècle Latin America". Perennial Decay: On the Aesthetics and Politics of Decadence. Ed. Liz Constable, et al. Pennsylvania: Pennsylvania UP, 1999. 183-197.

Morel, Bénédict A. Traité des dégénérescences physiques, intellectuelles, et morales de l'espèce humaine: et des causes qui produisent ces variétés maladives. Paris: J. B. Ballière, 1857.

Moreno, Isaac. "Licencia”. Manual del perfecto enfermo. Rafael Urbano. Madrid: Librería de Francisco Beltrán, 1911. 5-6.

Nordau, Max. Degeneración. Madrid: Fernando Fé, 1902.

Nouzeilles, Gabriela. "Narrar el cuerpo propio. Retórica modernista de la enfermedad”. Estudios. Revista de Investigaciones Literarias 5.9 (1997): 149-176.

Ficciones somáticas. Naturalismo, nacionalismo y políticas médicas del cuerpo (Argentina 1880-1910). Rosario: Beatriz Viterbo, 2000.

Ortiz, Teresa. Medicina, historia y género: 130 años de investigación feminista. Oviedo: KRK, 2006.

Pitarch, Pau. "Decadencia y modernidad en Alma contemporánea”. Trabajo de investigación no publicado. Universitat Autònoma de Barcelona, 2003. 
Pick, Daniel. Faces of Degeneration: A European Disorder, c. 1848-1918. Cambridge: Cambridge UP, 1989.

Sekula, Alan. "The Body and the Archive”. October 39 (1986): 3-64.

Simón, $\mathrm{M}^{\mathrm{a}}$ Carmen. “Amalia Domingo Soler: escritora espiritista”. Ex Libris. Homenaje al profesor José Fradejas Lebrero. Tomo 2. Coord. Antonio Lorente, et al. Madrid: UNED, 1993. 730-744.

Sobejano, Gonzalo. Nietzsche en España. Madrid: Gredos, 1967.

Sontag, Susan. La enfermedad y sus metáforas. Barcelona: Muchnik, 1980.

Spackman, Barbara. Decadent Genealogies. The Rethoric of Sickness from Baudelaire to D’Annunzio. Ithaca, London: Cornell UP, 1989.

Urbano, Rafael. Manual del perfecto enfermo (ensayo de mejora). Madrid: Librería de Francisco Beltrán, 1911. 